\title{
Core Inflation, Expectations and Inflation Dynamics in Brazil
}

\author{
Antônio Clécio de Brito ${ }^{1}$, Elano Ferreira Arruda ${ }^{2}$, Ivan Castelar ${ }^{3}$, Nicolino Trompieri Neto ${ }^{4} \&$ Cristiano Santos ${ }^{5}$ \\ ${ }^{1} \mathrm{PhD}$ Candidate (CAEN/UFC), Federal University of Ceará, Fortaleza, Brazil \\ ${ }^{2}$ Department of Applied Economics (DEA/CAEN/MAER/UFC), Federal University of Ceará, Fortaleza, Brazil \\ ${ }^{3}$ Department of Finance (CAEN/UFC), Federal University of Ceará, Fortaleza, Brazil \\ ${ }^{4}$ Department of Economics (UNIFOR), University of Fortaleza, Fortaleza, Brazil \\ ${ }^{5}$ Federal University of Alagoas, Santana do Ipanema, Brazil \\ Correspondence: Elano Ferreira Arruda, Avenida da Universidade, 2700 -2º Floor. Zip code: 60020-181. \\ Benfica-Fortaleza/CE, Brazil. Tel: 85-3366-7751. E-mail: elano@ufc.br
}

Received: February 27, 2019

Accepted: April 11, 2019

Online Published: April 25, 2019

doi:10.5539/ijef.v11n6p1

URL: https://doi.org/10.5539/ijef.v11n6p1

\begin{abstract}
This work investigates the adequacy of core inflation measures as indicators of forward-looking expectations in the hybrid new Keynesian Phillips curve (HNKPC) for the Brazilian economy. For that purpose, we use monthly data between January 2002 and August 2015 and the heteroscedasticity and autocorrelation consistent generalized method of moments (HAC-GMM). The results indicate that the HNKPC is a robust mechanism to model Brazilian inflation dynamics in the period analyzed; that the recent increase in the degree of indexation of the Brazilian economy seems to have contributed to the formation of a stronger inertial component of inflation; and also that the core inflation measures appear to be potential indicators to model forward-looking expectations in the HNKPC in Brazil. Furthermore, the inflation forecasts extracted from these models are statistically similar to those generated by models that use market prognoses from the Focus survey published by the Central Bank of Brazil. Therefore, the core inflation measures appear to have adequately anchored the inflation expectations in Brazil in the period analyzed.
\end{abstract}

Keywords: core inflation, expectations, Phillips Curve, HAC-GMM

\section{Introduction}

Since the adoption of the inflation targeting system in Brazil in 1999, the way that economic agents form expectations about the future behavior of inflation has played a relevant role in the conduction of monetary policy. The inflationary processes feed expectations of future inflation, limit the planning horizon of economic agents and make the task of anchoring expectations harder. In this context, the monetary authority has a huge responsibility and needs a prospective tool to model the inflation rate to guide control measures and signal more clearly which targets will be pursued.

In this respect, one of the main tools used to establish inflation targets and to anchor expectations by central banks is core inflation measures. Core inflation rates are relevant measures to guide monetary policy because they help to identify and diagnose the shocks that affect inflation, thus influencing expectations and helping to keep prices stable. Those measures are also employed to detect fundamental changes in prices, which might be caused by temporary demand pressures on productive capacity, permanent shocks in relative prices, or alterations of the economic agents' expectations of inflation.

One of the main ways to model the behavior of inflation dynamics and their relation with agents' expectations is the Phillips curve, according to which there is an inverse relation between wage inflation and unemployment, or also a direct relation between inflation and economic activity. Its most recent version, called the hybrid new Keynesian Phillips curve (HNKPC), has been used to test the validity of the trade-off between inflation and unemployment and to make inferences about the role of expectations, inflation inertia and the pass-through of the exchange rate to inflation dynamics.

In the international literature, there is no consensus among works. Some show that the HNKPC is a robust mechanism to explain dynamics (Galí \& Gertler, 1999; Galí, Gertler, \& Lopez-Salido, 2001) while others question its empirical relevance (Rudd \& Whelan, 2005). For Brazil, recent academic papers indicate that the 
Phillips curve is adequate to explain the dynamics of the country's inflation. However, the results are highly sensitive to the estimation methods and proxies adopted, especially regarding the indicators of inflation expectations. The main works use inflation forecasts extracted from the Focus survey, for the mean, median or first day of the month, or forecasts obtained from time series models (Mendonça, Sachsida, \& Medrano, 2012; Sachsida, 2013; Arruda, Oliveira, \& Castelar, 2017).

Despite the recent increase in the number of works about inflation dynamics in Brazil, there are almost no discussions about the possible gains related to inclusion of core inflation measures as indicators of forward-looking expectations in the HNKPC.

Therefore, this work tests the adequacy of core inflation measures as indicators of expectations in the HNKPC for the Brazilian economy. For that purpose, we use five core inflation measures as variables of forward-looking expectations. Besides the three main measures disclosed by the Brazilian Central Bank (BCB), we use two measures proposed by Santos (2017).

Therefore, we estimate five models of the HNKPC for Brazil, by means of the heteroscedasticity and autocorrelation consistent generalized method of moments (HAC-GMM), based on monthly data from January 2002 to August 2015 (Note 1), to examine the adequacy of the measures of core inflation as indicators of forward-looking expectations to model the dynamics of Brazilian inflation. Additionally, we perform inflation forecasting exercises with these models and compare them with models that employ the usual measures of the Focus survey from the BCB, by means of the predictive efficiency test of Diebold and Mariano (1995).

Besides this introduction, the paper is organized in four more sections. The second one presents the theoretical aspects and a brief literature review on core inflation measures and the HNKPC. The third section explains the methodological aspects involving the database and econometric strategy. The results are presented and discussed in the fourth section, and the fifth section presents the concluding remarks.

\section{Theoretical Aspects}

\subsection{Core Inflation}

The concept of core inflation was initially proposed by Eckstein (1981), who defined it as the part of inflation that is directly connected to inertial factors, such as agents' expectations. That inertial component is responsible for the rising trend of the costs of production factors. The author disaggregated inflation into the sum of three components: core inflation $\left(c_{t}\right)$, inflation due to aggregate demand $\left(d_{t}\right)$, and supply shocks $\left(s_{t}\right)$. In other words:

$$
\pi_{t}=c_{t}+d_{t}+s_{t}
$$

Therefore, Eckstein (1981) expressed the core as the long-term inflation rate in a stationary state, estimated in the absence of supply side shocks, $s_{t}$, and with the impact of demand, $d_{t}$, nil. In contrast, according to Quah and Vahey (1995), the core rate denotes the component of inflation that is incorporated in inflation expectations, but does not exert an impact on output in the medium to long run.

Despite its theoretical importance, there is no formal definition of core inflation, so many measures have been proposed, each with a different concept based on the method utilized. Roger (1998) described two important approaches to estimate core inflation: the core as persistent inflation, based on the quantitative theory of money; and the core as generalized inflation, which consists of identifying price changes that are permanent and those that are transitory.

Authors such as Bryan and Cecchetti (1994), Morana (2004, 2007), Andrade and O'Brien (2001), and Giannone and Matheson (2007) modelled core inflation as being the inflation caused by monetary expansion, i.e., a measure directly associated with the growth of the money supply in the economy. All these authors used the quantitative theory of money to establish a relation between variations of the level of prices in the economy based on variations in the money supply. In other words:

$$
M V=P Y
$$

where $M$ is the nominal money supply, $V$ is the velocity of transactions, $P$ is the price level, and $Y$ is output level. Therefore, inflation is affected in the long run only by monetary factors, such as the issuance of money. In this case, the central bank, as the conductor of monetary policy, has overall responsibility for controlling monetary inflation and the core rate. That theoretical approach considers the existence of a stationary state, according to which empirical works have indicated that the core can be measured as the long-term inflation trend.

The second approach, in which the core is estimated as a permanent component of the variation of prices, is based on the distinction between persistent inflation, which can be understood as an inflation trend, and 
transitory inflation, which represents the temporary shocks on prices (Santos \& Castelar, 2016). Therefore, researchers have investigated whether that component has a statistically relevant relation with the long-term path of the inflation variable, using different techniques to allow separating prices that are permanent from those that are merely transitory.

In this respect, since the monetary authority needs prospective tools to deal with inflation, core inflation measures have been widely used as auxiliary instruments in an attempt to correct deficiencies of the usual inflation metrics. In addition, several authors noted the fact that monetary policy has a delayed effect on the economy. Therefore, the monetary authority should analyze the likely future behavior of inflation before setting its policy. Within this current, Denardin, Kozakevicius, and Schmidt (2016), by focusing on the lags of the effects of monetary policy on the economy, stressed the need to have a leading indicator of the future inflation trend. In this sense, the monetary authority needs to act in a forward-looking manner, for which it needs a good measure of the future tendency of prices, a role that core inflation measures have been filling.

Therefore, by adding information about the future behavior of inflation, these core measures have become important tools to help monetary authorities make decisions, as well as to improve the ability of economic agents to make forecasts.

\subsection{Phillips Curve}

The origin of the Phillips curve dates to a statistical investigation published by the economist A. W. Phillips in 1958 , in which he analyzed the historical relationship between the unemployment rate and wage inflation variations in the United Kingdom between 1861 and 1957. In its traditional version, the curve has the following specification:

$$
\pi_{t}=\alpha+\gamma u_{t}+\varepsilon_{t}
$$

where $\pi_{t}$ is wage inflation at time $t, u_{t}$ is the current unemployment rate, and $\alpha$ and $\gamma$ are parameters, in which $\gamma<0$, and $\varepsilon_{t}$ is the error term.

According to Phillips, a high unemployment rate generates excess labor supply in the economy, which leads to a reduction of wage inflation. Thus, when the economy presents higher inflationary processes, real wages are lower, so firms are motivated to hire more workers. In other words, there is a trade-off between inflation and unemployment, by which the higher the jobless rate is, the lower inflation will tend to be, and vice versa.

During nearly all of the 1960s, the original formulation of the Phillips curve prevailed, becoming an important tool for macroeconomic policy. However, the scenario of stagflation in the 1980s in the United States led to repeated critiques regarding the adjustment of policies to control demand so as to deal with inflation and unemployment, changing the perception that the Phillips curve was a consistent and infallible rule by which higher inflation is always associated with less unemployment.

This situation prompted Taylor (1980) and Calvo (1983) to propose the bases for a more modern analysis of inflation, by examining the choice of prices and wages based on a micro-based framework of individuals and firms operating in a market structure of imperfect competition. The resulting curve, called the new Keynesian Phillips curve (NKPC), predicts a short-term relationship between inflation and a measure of the marginal cost of firms, besides considering the importance of forward-looking expectations. That relationship can be represented as:

$$
\pi_{t}=\lambda c m_{t}+\gamma_{f} E\left\{\pi_{t+1}\right\}
$$

Therefore, inflation at $t, \pi_{t}$, is expressed as a function of the expected inflation for the following period, $E\left\{\pi_{t+1}\right\}$, i.e., a component of forward-looking expectation, and by a measure of the economic cycle, such as the marginal cost of firms, $\mathrm{cm}_{t}$; output gap or unemployment gap.

Gali and Getler (1999) proposed to include an inertial inflation component, absent in the previous specification, and motivated the emergence of the version that became known as the hybrid new Keynesian Phillips curve (HNKPC). In this approach, the Phillips curve has two components in its specification, one for adaptive expectations (or backward-looking expectations) and the other component denoting rational, or forward-looking, expectations, represented as:

$$
\pi_{t}=\lambda c m_{t}+\gamma_{f} E\left\{\pi_{t+1}\right\}+\gamma_{b} \pi_{t-1}
$$

where $\gamma_{f}$ is the parameter of the rational expectation term, $\gamma_{b}$ incorporates the adaptive expectation of inflation, or the degree of inflationary persistence, and $\lambda$ encompasses the contribution of economic cycles to inflation.

More recently, the discussion of the impacts of supply shocks, such as exchange rate swings, on the inflation 
dynamics led to the formulation of Blanchard and Galí (2007) of the HNKPC. Specifically, the authors proposed to expand the hybrid model to enable expressing inflation also as a function of supply shocks:

$$
\pi_{t}=\lambda c m_{t}+\gamma_{f} E\left\{\pi_{t+1}\right\}+\gamma_{b} \pi_{t-1}+\theta v_{t}
$$

where $\theta$ measures the impact of supply shocks on inflation; and $v_{t}$ is a measure of the pass-through from the exchange rate to inflation, in the sense that a currency valuation will mean lower expenses of firms that use foreign inputs in their productive process, which can have a positive repercussion on profits, while a currency devaluation will mean higher costs, causing losses or markups to be squeezed.

\subsubsection{Empirical Evidence about the HNKPC for Brazil}

In recent decades, various works have sought to estimate the Phillips curve for Brazil. Using monthly data between 1996:1 and 2006:1, Tombini and Alves (2006) analyzed possible structural breaks in the parameters of a hybrid Phillips curve. For this purpose, the authors estimated a Phillips curve with variable coefficients and observed that the values of several of these coefficients moved to distinct levels in the switch to the floating exchange rate in 1999. They found the impacts of backward-looking and forward-looking expectations to be similar, with the coefficients of the variables oscillating between 0.1 and 0.3 .

Areosa and Medeiros (2007), using monthly data for the Brazilian economy during the period from 1991:1 to 2009:08, estimated a hybrid new Keynesian Phillips curve by the generalized method of moments (GMM). They then tested the importance of the exchange rate component in a small open economy vis-à-vis a closed economy. The results indicated that the inertial component was not negligible, with significant estimates of around 0.45; forward-looking expectations had a stronger impact, with values of around 0.53 ; and the impact of economic cycles measured by the output gap was not statistically significant.

Mazali and Divino (2010) estimated a Phillips curve employing quarterly data covering the period from 1995:1 to 2008:4, applying the generalized method of moments (GMM). Their econometric results indicated good fit of the Phillips curve to the Brazilian data. The coefficients estimated were on the order of 0.59 for inertial inflation, 0.44 for forward-looking expectations and -0.13 for unemployment.

Relying on quarterly data between 1995 and 2004, Correa and Minella (2010) analyzed the presence of nonlinear mechanisms in the pass-through of the exchange rate to inflation, using a threshold autoregressive (TAR) model to model the HNKPC, considering three threshold variables to capture the change in the foreign exchange regime: the output gap, fluctuations of the nominal exchange rates and exchange rate volatility. The model was estimated by two-stage least squares (2SLS) to test instrumental variables for expectations. In the first model, the estimated coefficients of the forward-looking and backward-looking expectations were 0.62 and 0.29 , respectively, the impact of the cycles was 0.15 and the pass-through of the exchange rate was on the order of 0.09 . In the second model, the inflation inertia component was 0.34 , that of forward-looking expectations was 0.63 , and the impacts of the exchange rate pass-through and economic cycles were 0.10 and 0.22 , respectively. Lastly, the influences of the forward-looking and backward-looking expectations were 0.66 and 0.30 , respectively. The cycles had an impact of around 0.20 and the coefficient of the exchange rate pass-through was 0.04.

Arruda, Ferreira and Castelar (2011) estimated linear and nonlinear models of the Phillips curve to forecast Brazilian inflation. They found that the Phillips curve with a nonlinear specification presented the best predictive performance, including better forecasts than the Central Bank's Focus survey. The estimated coefficients obtained for the linear Phillips curve were significant and of the order of 0.71 for inflation inertia and 1.58 for the exchange rate pass-through. When considering the nonlinear model (in a regime of high inflation), past inflation presented an impact of 0.69 and the pass-through of the exchange rate to inflation was 2.62. The output gap was not significant in any of the models.

Mendonça, Sachida, and Medrano (2012) estimated a HNKPC using monthly data for the period from 1995:1 to 2012:3, by applying instrumental variables and the HAC-GMM. They observed coefficients between 0.25 and 0.53 for the forward-looking component, between 0.41 and 0.52 for inflation inertia, and between 0.26 and 0.55 for the exchange rate pass-through.

Utilizing monthly data between 2002:1 and 2015:8, Arruda, Oliveira and Castelar (2017) examined the recent dynamics of Brazilian inflation considering distinct scenarios of forward-looking expectations in the HNKPC, through the HAC-GMM. For this, the authors used four expectation variables, one in the scenario of perfect prediction, one employing the consumer price index (IPCA) itself as a measure of forward-looking expectations, and three other measures, obtained from the BCB's Focus survey, as proxies for future inflation of agents, namely the mean, median and expectation of the first day of the following month. Under the hypothesis of uncertainty, the magnitude of the coefficients of inflation inertia varied from 0.52 to 0.69 , the impacts of 
forward-looking expectations oscillated between 0.13 and 0.46 , and the effects of unemployment ranged between -0.53 and -0.65 . The exchange rate pass-through also presented significant impacts, varying from 0.003 to 0.006 .

Table 1. Evidence for Brazil

\begin{tabular}{|c|c|c|c|c|c|}
\hline Authors & $\begin{array}{c}\text { Inflationary } \\
\text { Inertia } \\
\end{array}$ & $\begin{array}{c}\text { Forward-Looking } \\
\text { Expectations }\end{array}$ & $\begin{array}{c}\text { Economic } \\
\text { Cycles }\end{array}$ & Pass-through & Sample \\
\hline Tombini and Alves (2006) & $\begin{array}{l}\text { Between } 0.1 \\
\text { and } 0.3\end{array}$ & Between 0.1 and 0.3 & NS & - & 1996: M1 to 2006: M1 \\
\hline Areosa and Medeiros (2007) & 0.45 & 0.53 & NS & - & 1995: M1 to 2003: M9 \\
\hline Mazali and Divino (2010) & 0.59 & 0.44 & -0.13 & - & 1995: M1 to 2008: M4 \\
\hline Correa and Minella (2010) - model1 & 0.29 & 0.62 & 0.15 & 0.09 & 1995: Q1 to 2004: Q4 \\
\hline Correa and Minella (2010) - model 2 & 0.34 & 0.63 & 0.22 & 0.10 & 1995: Q1 to 2004: Q4 \\
\hline Correa and Minella (2010) - model 3 & 0.30 & 0.66 & 0.20 & 0.04 & 1995: Q1 to 2004: Q4 \\
\hline $\begin{array}{c}\text { Arruda, Ferreira and Castelar (2011) - } \\
\text { Linear }\end{array}$ & 0.71 & - & NS & 1.58 & 1995: M1 to 2005: M12 \\
\hline $\begin{array}{l}\text { Arruda, Ferreira and Castelar (2011) - } \\
\text { Non Linear }\end{array}$ & 0.69 & - & NS & 2.62 & 1995: M1 to 2005: M12 \\
\hline $\begin{array}{l}\text { Mendonça, Sachida and Medrano } \\
\text { (2012) }\end{array}$ & $\begin{array}{l}\text { Between } 0.41 \\
\text { and } 0.52\end{array}$ & $\begin{array}{c}\text { Between } 0.25 \text { and } \\
0.53\end{array}$ & NS & $\begin{array}{l}\text { Between } 0.26 \\
\text { and } 0.55\end{array}$ & 1995: M1 to 2012: M3 \\
\hline $\begin{array}{l}\text { Mendonça, Sachida and Medrano } \\
\text { (2012) }\end{array}$ & 0.39 & $\begin{array}{c}\text { Between } 0.63 \text { and } \\
0.67\end{array}$ & NS & NS & 2002: M1 to 2012: M3 \\
\hline Arruda, Oliveira and Castelar (2017) & $\begin{array}{c}\text { Between } 0.52 \\
\text { and } 0.69\end{array}$ & $\begin{array}{c}\text { Between } 0.13 \text { and } \\
0.46\end{array}$ & $\begin{array}{c}\text { Between } 0.53 \\
\text { and } 0.65\end{array}$ & $\begin{array}{c}\text { Between } 0.003 \\
\text { and } 0.006\end{array}$ & 2002: M1 to 2015: M8 \\
\hline Ferreira, Goes and Arruda (2018) & $\begin{array}{l}\text { Between } 0.61 \\
\text { and } 0.68\end{array}$ & $\begin{array}{c}\text { Between } 0.42 \text { and } \\
0.44\end{array}$ & $\begin{array}{l}\text { Between }-0.15 \\
\text { and }-0.16\end{array}$ & - & 2001: M7 to 2014: M12 \\
\hline
\end{tabular}

Source: Prepared by the authors.

Note 1. (NS) Not Significant; (-) Did not use the variable; (Q) - Quarterly data; (M) - Monthly data.

Using credibility indices as threshold variables for the Brazilian economy, Ferreira, Goes and Arruda (2018) estimated a HNKPC to verify if different credibility levels of the Central Bank influence the inflation dynamics in Brazil. For this, the authors used monthly data running from 2001.7 to 2014.12 and threshold models like those of Caner and Hansen (2004). The results showed that in the low credibility regime, inflation was more sensitive to the cycles and to its inertial component, with the forward-looking component not being statistically significant. In the high credibility situation, they did not find a trade-off between inflation and unemployment. The coefficients of expectations varied between 0.42 and 0.44 , while those of inflation inertia ranged from 0.61 to 0.68 and the impact of the unemployment gap fluctuated from -0.15 to -0.16 .

To summarize, as argued by Sachsida (2013), the Phillips curve appears to be an adequate form of explaining the dynamics of Brazilian inflation. However, the results are highly sensitive to the proxies used, especially in relation to the inflation expectations. In the present work, we intend to contribute to the literature by examining the adequacy of core inflation measures as forward-looking components in the HNKPC. Table 1 presents a summary of the evidence observed for Brazil.

\section{Methodological Aspects}

\subsection{Description of the Core Inflation Measures}

The Brazilian Central Bank (BCB) currently discloses information about five core inflation measures, all of them referenced to the IPCA, the official inflation index adopted in the targeting regime. These are: the core by exclusion without monitored prices and cost of foods consumed at home (IPCA-EX), the core by exclusion that removes only the items that consistently are more volatile over the sample (IPCA-EX2), the double-weighted core (IPCA-DP), the core obtained by trimmed means without smoothing (IPCA-MA), and the core obtained by trimmed means with smoothing (IPCA-MS). Santos and Castelar (2016) argue that the two core measures by exclusion (IPCA-EX and IPCA-EX2) are not reliable leading indicators of inflation, given the arbitrary way of excluding items. Based on this observation, we do not use these two measures here.

As an alternative to the methods by exclusion, we include core measures obtained from limited-influence estimators (LIEs), which reduce the influence of the values located at the extremes (tails) of the distribution. The 
trimmed mean without smoothing method (IPCA-MA) is a general example of the class of limited-influence estimators, for which the mean of the distribution is calculated from a cross-section of prices, disregarding the extremes (trimmed tails). In other words, $40 \%$ of the items that have extreme variations are eliminated, $20 \%$ from each tail of the distribution, and the inflation index is recalculated using only the central part of the distribution, considering the original weight of each item.

In contrast, in the IPCA-MS core measure, since some administered prices present components with less frequent alterations, disregarding these items could generate a downward bias and to exclude relevant information about the persistent component of inflation. To avoid this problem, the BCB smooths these series into 12 equal parts.

Unlike the core measures described so far, the calculation of the double-weighted core rate (IPCA-DP) does not exclude any item from the IPCA, but adjusts the original weight of each item according to its relative volatility, i.e., in this approach, the greater the relative volatility of an item that composes the basic consumer basket is, the lower will be its weight in calculating the core. To compute the relative volatility, the BCB use a 48-month moving average (BCB, 2009).

Besides the usual measures disclosed by the $\mathrm{BCB}$, we include two additional measures, proposed by Santos (2017), the core extracted from empirical mode decomposition (CORE-EMD), here called IPCA-EMD, and the core constructed from the unobserved multivariate components (IPCA-CP2). The author showed that these metrics, besides having forward-looking characteristics, are better indicators of IPCA inflation than those proposed by the BCB.

The IPCA-EMD is an alternative core measure that can be estimated by a variant of the empirical mode decomposition, called complete ensemble empirical mode decomposition with adaptive noise (CEEMDAN). This measure has a partial reconstruction property that is able to deal with nonstationary series and those with nonlinear behavior, besides efficiently distinguishing the persistent part of inflation from its temporary component. For a detailed description, see Santos (2017).

The IPCA-CP2 is a measure extracted from an unobserved components model with multivariate characteristic that incorporates the inflation variables, measured by the IPCA, and the basic interest rate in Brazil, the SELIC. Santos (2017) also highlighted the good performance of this core measure versus those proposed by the BCB. Table 2 below summarizes the core measures used in this study.

Table 2. Core inflation measures

\begin{tabular}{ccc}
\hline Type & Measure & Description of the measure \\
\hline Double-Weighted Measures & IPCA-DP & Adjusts the original weight of each item according to its relative volatility (48 monthly) \\
& IPCA-MA & Trimmed Mean Measures without smoothing \\
Trimmed Mean Measures & IPCA-MS & Trimmed Mean Measures with smoothing \\
Empirical Mode Decomposition & IPCA-EMD & Complete Ensemble Empirical Mode Decomposition with Adaptive Noise (CEEMDAN) \\
Unobserved Components Model & IPCA-CP2 & Unobserved Components Model with Multivariate Characteristic with IPCA and SELIC \\
\hline Source: Prepared by the authors. & &
\end{tabular}

\subsection{Database}

To estimate the HNKPC, we collected monthly data from January 2002 to August 2015 for the Brazilian economy. The sample period was chosen due to the unavailability of more recent data for all the variables employed. The inflation indicator used is measured by the Comprehensive Consumer Price Index (IPCA). The data are available from the National System of Consumer Price Indices (SNIPC) of the Brazilian Institute of Geography and Statistics (IBGE).

To ascertain the adequacy of the core inflation measures as indicators of forward-looking expectations in the HNKPC, we use five alternatives for this variable, three of them officially disclosed by the BCB (IPCA-MA, IPCA-MAS and IPCA-DP), and two proposed by Santos (2017), IPCA-EMD and IPCA-CP2.

The variable that incorporates the inertial (or backward-looking) component is the lagged IPCA, as is the standard practice in the literature. The economic cycle measure used is the unemployment gap, constructed by applying the Hodrick-Prescott (HP) filter. Finally, inspired by Correa and Minella (2010) and Arruda, Ferreira and Castelar (2011), we use as the indicator of the exchange rate pass-through to inflation the variable $\left(\Delta e_{t}+\pi_{t}^{*}\right)$, where $e_{t}$ is the logarithm of the nominal exchange rate, $\Delta$ is the difference operator, and $\pi_{t}^{*}$ is the producer price inflation in the United States (PPI). Table 3 summarize the variables used. 


\subsection{Econometric Strategy}

Table 3. Description of the variables

\begin{tabular}{cccc}
\hline INDICATOR & VARIABLE & PROXY & SOURCE \\
\hline Inflation & Inflation & Consumer Price Index (IPCA) & IBGE/SNIPC \\
& & IPCA-MA & BCB-Depec \\
& & IPCA-MAS & BCB-Depec \\
& Core Inflation & IPCA-EX & BCB-Depec \\
Expectations & Measures & IPCA-EX2 & BCB-Depec \\
& & IPCA-DP & BCB-Depec \\
& & IPCA-EMD & BCB-Depec \\
Economic Cycles & Unemployment Cycle & IPCA-CP2 & IBGE and HP filter \\
& Eass-through & Unemployment gap & BCB-Depec and IFS/FMI \\
\hline
\end{tabular}

Source: Prepared by the authors.

Among the econometric techniques to estimate rational expectation models, the generalized method of moments (GMM), introduced by Hansen (1982), has been widely employed, since in the presence of endogenous regressors, the ordinary least squares (OLS) method can generate inconsistencies due to the probable correlation between the error term and those regressors. Alternatively, some authors have opted to use models with instrumental variables (IV) (Note 2). However, as shown by Baum, Schaffer, and Stillman $(2003 ; 2007)$, in the presence of heteroscedasticity the GMM is more suitable.

Therefore, to select the estimation technique used in the models of this work, we first applied the heteroscedasticity test of Pagan and Hall (1983) (Note 3) in the estimation by instrumental variables (IV). Also, we applied the test of Cumby and Huizinga (1992) for serial autocorrelation, in which the absence of autocorrelation is the null hypothesis. Hence, if the null hypothesis of homoscedasticity is rejected in the Pagan-Hall test, GMM estimation is used. Furthermore, if the presence of serial autocorrelation is detected, the HAC-GMM should be used, which is a GMM estimator with correction for both problems.

Hansen (1982) demonstrated that if the instruments are valid, in the sense of being correlated with the endogenous regressors and not correlated with the error term, the GMM estimators are consistent and asymptotically normal. Therefore, we use the overidentification test of Hansen (1982), in which the null hypothesis is that the instruments are valid. When the null hypothesis is not rejected, the instruments are assumed to be valid and the model to be adequately estimated. The models estimated use instruments with up to six lags for inflation, unemployment gap and interest rate, as done by Galí and Gertler (1999).

Therefore, the five models estimated in this work and their respective orthogonality conditions in the estimation by GMM can be represented by the equations below, in which $z_{t}$ is the vector of instrumental variables.

$$
\begin{gathered}
\pi_{t}=\lambda c m_{t}+\gamma_{f} E_{t}\left\{\pi_{t+1}\right\}+\gamma_{b} \pi_{t-1}+\theta v_{t}+\varepsilon_{t} \\
E_{t}\left\{\left(\pi_{t}-\lambda c m_{t}-\gamma_{f} \pi_{t+1}-\gamma_{b} \pi_{t-1}-\theta v_{t}\right) z_{t}\right\}=0
\end{gathered}
$$

After analyzing the fit of the core variables in the HNKPC, we conducted a prediction exercise in which the inflation forecasts generated by the five models were compared to the prognoses produced by HNKPC models that employ the usual measures of the BCB's Focus survey, namely mean, median and first day of the month expectation. The aim of this additional analysis is to make inferences about the predictive efficiency of these models of the HNKPC with core inflation measures as forward-looking indicators, versus models with other measures traditionally used in the literature.

Therefore, to compare the predictive efficiency of these models, it is necessary to consider a decision criterion, to judge how precise the prognosis obtained from a determined model is. In line with West (2006), if the objective is to forecast future values of a time series that are subject to the smallest possible error, one of the suitable criteria to compare forecasts is the mean square error of prediction (MSEP), given by:

$$
M S E P=\frac{\sum_{t=R+1}^{R+P}\left(Y_{t}^{F}-Y_{t}\right)^{2}}{P}
$$

where $Y_{t}^{F}$ denotes the predicted value and $Y_{t}$ is the observed value of the variable of interest. Besides using the MSEP as a measure of the predictive efficiency and to select the best models, we also use the procedure described by West (2006), illustrated by the diagram below: 


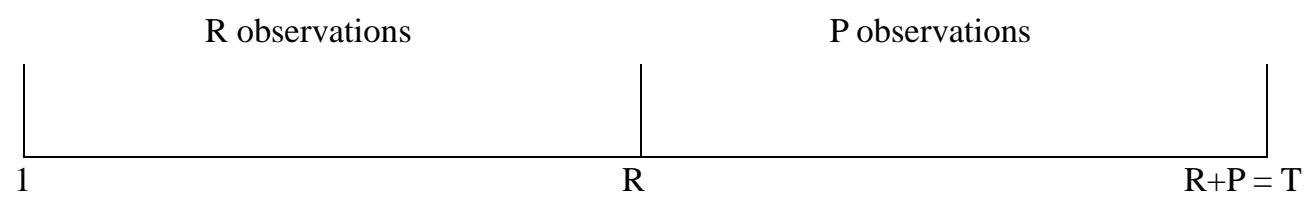

Figure 1. Prediction diagram

Source: West (2006).

In other words, the total sample used in this study corresponds to monthly data from January 2002 to August 2015, ( $\mathrm{T}$ in the diagram). All the models are estimated using data from January 2002 to June 2014 ( $R$ observations in the diagram). Then forecasts are generated for the period from July 2014 to July 2015, from R+1 to $\mathrm{R}+\mathrm{P}$, ( $\mathrm{P}$ periods based on Equation 9 in the diagram above).

After generating the forecasts, we calculate the MSEP of each model to observe those that produce more effective results, i.e., with the smallest MSEP. Then, we use the test of Diebold and Mariano (1995) to compare the forecasts. This test consists of analyzing the losses associated with each of the forecasts based on a statistical criterion to evaluate the equality of their predictive performances. Thus, the null hypothesis is that the models have similar predictive efficiency.

To summarize, the econometric strategy employed here can be described as: first we investigate the presence of heteroscedasticity and serial autocorrelation in the estimation of the instrumental variables via the tests of Pagan and Hall (1983) and Cumby and Huizinga (1992), respectively (Note 4). If the presence of heteroscedasticity is found, use the GMM with correction for this problem, and if the presence is also detected of serial autocorrelation, apply the correction for both problems, i.e., the HAC-GMM. Then, we apply the Hansen (1982) test to ascertain the validity of the instruments, and if the null hypothesis is not rejected, the instruments will be deemed valid and the model will be adequately estimated. Lastly, we analyze the predictive efficiency of the prognoses generated by the models against the models that employ the indicators traditionally used in the HNKPC.

\section{Analysis and Discussion of the Results}

To estimate the models of the HNKPC considering core inflation measures as indicators of forward-looking expectations, we first verified the stationarity of the series by applying the usual unit root tests, such as the augmented Dickey-Fuller (ADF) test and the Kwiatkowoski, Phillips, Schmidt, and Shin (1992) (KPSS) test. Table 4 summarizes the results of these tests, which confirmed that all the series were stationary at $5 \%$ level of significance.

Table 4. Unit Root Tests

\begin{tabular}{lll}
\hline VARIABLE & ADF & KPSS \\
\hline Inflation IPCA & -5.07 & 0.24 \\
& {$[-2.87]$} & {$[0.46]$} \\
IPCA.MA & -4.63 & 0.25 \\
& {$[-2.87]$} & {$[0.46]$} \\
IPCA.MAS & -3.87 & 0.40 \\
IPCA.DP & {$[-2.87]$} & {$[0.46]$} \\
& -4.45 & 0.28 \\
IPCA.EMD & {$[-2.87]$} & {$[0.46]$} \\
& -2.96 & 0.35 \\
IPCA.CP2 & {$[-2.87]$} & {$[0.46]$} \\
& -3.01 & 0.15 \\
Unemployment Gap & {$[-2.87]$} & {$[0.46]$} \\
& -6.02 & 0.02 \\
Exchange Rate Pass-through & {$[-2.87]$} & {$[0.46]$} \\
\hline
\end{tabular}

Source: Prepared by the authors.

Note 1. Critical value of the test at significance level $5 \%$ expressed in brackets.

Note 2. The null hypothesis of the ADF tests is that the series has a unit root, whereas in the KPSS it is that the series are stationary. 
Then, according to the methodological strategy described in the previous section, the Pagan and Hall (1983) test indicated the presence of heteroscedasticity in all the cases analyzed, so the decision was made to use the GMM in all cases. The results of the Cumby and Huizinga (1992) test indicated the absence of autocorrelation of the models considering the IPCA-MAS, IPCA-CP2 and IPCA-EMD as indicators of forward-looking expectations, meaning those models could be estimated by GMM with correction only for heteroscedasticity. In the other regressions, we employed correction for both the problems, i.e., the HAC-GMM. Furthermore, the results of the Hansen (1982) test revealed it was not possible to reject the null hypothesis of validity of the instruments in all the models analyzed. Therefore, all the models were adequately estimated. The results are summarized in Table 5 .

Table 5. Estimation of the HNKPC with HAC-GMM

\begin{tabular}{|c|c|c|c|c|c|c|c|}
\hline \multirow{2}{*}{$\begin{array}{c}\text { Expectations } \\
\text { (Core Inflation measures) }\end{array}$} & \multicolumn{4}{|c|}{ Parameters } & \multirow{2}{*}{$\begin{array}{c}\text { J-Test } \\
\text { Hansen }\end{array}$} & \multirow{2}{*}{$\begin{array}{c}\text { Heterocedasticity } \\
\text { Pagan and Hall } \\
\end{array}$} & \multirow{2}{*}{$\begin{array}{c}\text { Autocorrelation } \\
\text { Cumby and Huizinga }\end{array}$} \\
\hline & $\lambda$ & $\gamma_{f}$ & $\gamma_{b}$ & $\theta$ & & & \\
\hline IPCA.MA & $\begin{array}{l}-0.42 \\
(0.00)\end{array}$ & $\begin{array}{c}0.47 \\
(0.01)\end{array}$ & $\begin{array}{c}0.54 \\
(0.00)\end{array}$ & $\begin{array}{l}0.005 \\
(0.00)\end{array}$ & $\begin{array}{l}10.22 \\
(0.74)\end{array}$ & $\begin{array}{c}\chi^{2}(39)=53.62 \\
(0.05)\end{array}$ & $\begin{array}{c}\chi^{2}(1)=7.82 \\
(0.00)\end{array}$ \\
\hline IPCA.MAS & $\begin{array}{l}-0.51 \\
(0.00)\end{array}$ & $\begin{array}{c}0.38 \\
(0.00)\end{array}$ & $\begin{array}{c}0.54 \\
(0.00)\end{array}$ & $\begin{array}{l}0.006 \\
(0.77)\end{array}$ & $\begin{array}{l}9.76 \\
(0.78)\end{array}$ & $\begin{array}{c}\chi^{2}(15)=31.77 \\
(0.00)\end{array}$ & $\begin{array}{c}\chi^{2}(1)=0.40 \\
(0.52)^{*}\end{array}$ \\
\hline IPCA.DP & $\begin{array}{l}-0.43 \\
(0.00)\end{array}$ & $\begin{array}{c}0.46 \\
(0.00)\end{array}$ & $\begin{array}{c}0.52 \\
(0.00)\end{array}$ & $\begin{array}{l}0.005 \\
(0.00)\end{array}$ & $\begin{array}{l}10.16 \\
(0.75)\end{array}$ & $\begin{array}{c}\chi^{2}(39)=52.7 \\
(0.06)^{* *}\end{array}$ & $\begin{array}{c}\chi^{2}(1)=16.19 \\
(0.00)\end{array}$ \\
\hline IPCA.CP2 & $\begin{array}{l}-0.61 \\
(0.00)\end{array}$ & $\begin{array}{c}0.36 \\
(0.02)\end{array}$ & $\begin{array}{c}0.62 \\
(0.00)\end{array}$ & $\begin{array}{l}0.003 \\
(0.36)\end{array}$ & $\begin{array}{c}6.70 \\
(0.56)\end{array}$ & $\begin{array}{c}\chi^{2}(15)=25.67 \\
(0.04)\end{array}$ & $\begin{array}{c}\chi^{2}(1)=0.21 \\
(0.64)^{*}\end{array}$ \\
\hline IPCA.EMD & $\begin{array}{l}-0.68 \\
(0.00)\end{array}$ & $\begin{array}{c}0.42 \\
(0.01)\end{array}$ & $\begin{array}{c}0.56 \\
(0.00)\end{array}$ & $\begin{array}{l}0.003 \\
(0.39)\end{array}$ & $\begin{array}{c}8.42 \\
(0.39)\end{array}$ & $\begin{array}{c}\chi^{2}(15)=26.18 \\
(0.03)\end{array}$ & $\begin{array}{c}\chi^{2}(1)=0.55 \\
(0.45)^{*}\end{array}$ \\
\hline
\end{tabular}

Source: Prepared by the authors on the basis of the equation $\pi_{t}=\lambda c m_{t}+\gamma_{f} E_{t}\left\{\pi_{t+1}\right\}+\gamma_{b} \pi_{t-1}+\theta v_{t}$.

Note 1. P-value in parenthesis.

Note 2. The autocorrelation and heteroscedasticity tests were applied in the IV estimation

Note 3. (*) Model corrected for heteroscedasticity only.

Note 4. (**) Significant at the $10 \%$ level.

Based on these results, in can be stated that in general the HNKPC is suitable to explain the inflation dynamics in Brazil in the period analyzed, given that in all the models, the variables were statistically significant and had the signs predicted in the literature.

The evidence suggests that the core inflation measures are appropriate indicators to model forward-looking expectations in the HNKPC, since the five measures employed here were statistically robust. Their coefficients varied between 0.36 and 0.47 , meaning that an increase of 1 percentage point in future inflation expectations had an impact of 0.36 p.p. to 0.47 p.p. on the inflation dynamics, respectively. These impacts have a similar magnitude to those observed in recent works, such as those of Arruda, Oliveira and Castelar (2017) and Ferreira, Gois and Arruda (2018). These results corroborate the hypothesis formulated by Santos and Castelar (2016) that core inflation measures are good leading indicators of Brazilian inflation dynamics, exerting an important role in the conduction of monetary policy.

The results further revealed that the estimated coefficients of the impact of inflation inertia were greater than those of forward-looking expectations, with magnitudes ranging between 0.52 and 0.62 . This result appears to indicate a recent evolution of the level of indexation of the economy, in line with the findings of Carvalho (2014) and Arruda, Oliveira, and Castelar (2017), since some authors who estimated the NKPC for earlier periods observed a stronger influence of forward-looking expectations (Areosa \& Medeiros, 2007; Correa \& Minella, 2010; Mendonça, Sachida, \& Medrano, 2012).

Furthermore, we observed the occurrence of a trade-off between inflation and unemployment in all the models analyzed, whereby for each increase of 1 p.p. in the deviation of unemployment from its natural level, inflation receded between 0.42 p.p. and 0.68p.p. Mendonça, Sachsida, and Medrano (2012), Arruda, Oliveira, and Castelar (2017) and Ferreira, Goes, and Arruda (2018) also obtained similar evidence. 
Table 6. Forecast summary

\begin{tabular}{cccccccccc}
\hline MONTHLY & IPCA & $\begin{array}{c}\text { HNKPC } \\
\text { IPCA.MA }\end{array}$ & $\begin{array}{c}\text { HNKPC } \\
\text { IPCA.MS }\end{array}$ & $\begin{array}{c}\text { HNKPC } \\
\text { IPCA.DP }\end{array}$ & $\begin{array}{c}\text { HNKPC } \\
\text { IPCA.CP2 }\end{array}$ & $\begin{array}{c}\text { HNKPC } \\
\text { IPCA.EMD }\end{array}$ & $\begin{array}{c}\text { FOCUS } \\
\text { MEAN }\end{array}$ & $\begin{array}{c}\text { FOCUS } \\
\text { MEDIAN }\end{array}$ & $\begin{array}{c}\text { FOCUS } \\
1 \text { st Day }\end{array}$ \\
\hline 2014.7 & 0.01 & 0.53 & 0.52 & 0.53 & 0.53 & 0.52 & 0.40 & 0.37 & 0.34 \\
2014.8 & 0.25 & 0.25 & 0.27 & 0.23 & 0.28 & 0.28 & 0.25 & 0.29 & 0.29 \\
2014.9 & 0.57 & 0.40 & 0.42 & 0.40 & 0.52 & 0.47 & 0.49 & 0.48 & 0.51 \\
2014.10 & 0.42 & 0.64 & 0.60 & 0.67 & 0.69 & 0.65 & 0.69 & 0.65 & 0.69 \\
2014.11 & 0.51 & 0.70 & 0.64 & 0.68 & 0.59 & 0.58 & 0.71 & 0.68 & 0.77 \\
2014.12 & 0.78 & 0.76 & 0.75 & 0.77 & 0.68 & 0.71 & 1.02 & 1.00 & 1.07 \\
2015.1 & 1.24 & 0.80 & 0.76 & 0.78 & 0.71 & 0.71 & 0.98 & 0.92 & 1.06 \\
2015.2 & 1.22 & 1.04 & 1.00 & 1.01 & 1.00 & 0.93 & 1.35 & 1.26 & 1.31 \\
2015.3 & 1.32 & 0.99 & 1.01 & 0.96 & 0.94 & 0.91 & 1.03 & 0.91 & 0.94 \\
2015.4 & 0.71 & 0.95 & 0.93 & 0.96 & 0.93 & 0.89 & 0.90 & 0.79 & 0.77 \\
2015.5 & 0.74 & 0.64 & 0.65 & 0.64 & 0.58 & 0.57 & 0.68 & 0.65 & 0.56 \\
2015.6 & 0.79 & 0.54 & 0.56 & 0.51 & 0.56 & 0.55 & 0.57 & 0.55 & 0.51 \\
2015.7 & 0.62 & 0.62 & 0.64 & 0.67 & 0.60 & 0.55 & 0.48 & 0.42 & 0.42 \\
MSEP Results & 0.0650 & 0.0631 & 0.0718 & 0.0743 & 0.0762 & 0.0463 & 0.0550 & 0.0520 \\
\hline
\end{tabular}

Source: Prepared by the authors.

Table 7. Results of the Diebold and Mariano tests

\begin{tabular}{cccccc}
\hline Comparing & HNKPC & HNKPC & HNKPC & HNKPC & $\begin{array}{c}\text { HNKPC } \\
\text { Forecasts }\end{array}$ \\
IPCA.MA & IPCA.MS & IPCA.DP & IPCA.CP2 & IPCA.EMD \\
\hline HNKPC FOCUS MEDIAN & 1.42 & 1.53 & 1.43 & 1.49 & 1.43 \\
& $(0.15)$ & $(0.12)$ & $(0.15)$ & $(0.13)$ & $(0.15)$ \\
HNKPC FOCUS MEAN & 1.61 & 1.23 & 1.72 & 1.68 & 1.50 \\
HNKPC FOCUS 1st DAY & $(0.10)$ & $(0.21)$ & $(0.08)$ & $(0.09)$ & $(0.13)$ \\
& 0.96 & 0.74 & 1.15 & 0.99 & 0.97 \\
& $(0.33)$ & $(0.45)$ & $(0.24)$ & $(0.31)$ & $(0.32)$ \\
\hline
\end{tabular}

Source: Prepared by the authors.

Note 1. P-value in parenthesis.

The exchange rate pass-through was statistically significant in two of the models, IPCA.MA and IPCA.DP. This result suggests that firms that use imported inputs in their productive process are passing through part of the higher costs to their prices. This finding corroborates the results reported by Correa and Minella (2010) and Arruda, Ferreira and Castelar (2011).

For the sake of comparison, we undertook an exercise in the molds described in the previous section. The results are summarized in Table 6 and indicate that the measures of mean square error of prediction (MSEP) had values considered low and very close among the models. Besides this, the results of the test of Diebold and Mariano (1995), reported in Table 7, indicate that the HNKPC with the core measures had statistically similar predictive efficiency to those used in the Focus survey, since they did not reject the null hypothesis that the models are equally effective for forecasting, at $5 \%$ significance.

Therefore, in view of the good performance of the models of the HNKPC using the cores and the similar predictive efficiency to the models employing indicators of the Focus survey, it can be concluded that the core inflation measures appear to have adequately anchored inflation expectations in Brazil in the period analyzed.

In short, the evidence found in this work allows the conclusion that the core inflation measures are appropriate alternatives to capture the effects of forward-looking expectations in the HNKPC for the Brazilian economy. We point out that these measures have a low construction cost, since there is no need to conduct a survey involving interviews with economic agents.

\section{Concluding Remarks}

Recent studies point out to HNKPC as an appropriate tool to model Brazilian inflation dynamics. However, their results are quite sensitive to the proxies adopted, mainly the ones to represent forward expectations (Sachsida, 2013). The main contribution of this paper, therefore, was to use core inflation measures to represent forward expectations and check if the estimated HNKPC produced parameter estimates in line with other studies and if it 
performed at least as well in predicting inflation as compared to alternative models.

In general, the evidence confirmed the ability of the HNKPC to model Brazil's inflation dynamics in the period considered, since the variables were statistically significant and had the signs predicted by the theory. This result also is supported by the works of Areosa and Medeiros (2007), Correa and Minella (2010), Mendonça, Sachsida and Medrano (2012) and Arruda, Oliveira and Castelar (2017).

The results indicate that Brazilian inflation has an important inertial component, since the impact of backward-looking expectations was greater than that of the forward-looking component in all the models considered. Similar results were also reported by Arruda, Oliveira, and Castelar (2017). According to Carvalho (2014), although the Real Plan (Note 5) reduced the velocity of price adjustments, it did not fully end indexation in the economy, and in recent years the degree of indexation has begun to rise again, which might have increased the impact of inertia on inflation.

The evidence also indicates the existence of a statistically significant trade-off between inflation and unemployment, with impacts varying between -0.68 and -0.42 , meaning that each increment of 1 p.p. in the deviation of unemployment from its natural level tends to reduce inflation by between 0.42p.p. and 0.68p.p., respectively. Also, in two models we observed a positive and statistically robust exchange rate pass-through, a result that corroborates the findings of Correa and Minella (2010), Arruda, Ferreira, and Castelar (2011) and Arruda, Oliveira, and Castelar (2017).

Lastly, the results also indicate that the core inflation measures are good proxies to model the forward-looking expectations in the HNKPC for the Brazilian economy, given that the five measures employed were statistically significant and had magnitudes in line with those reported in recent works. Besides this, the results of the test of Diebold and Mariano (1995) demonstrated that the inflation levels generated by these models were statistically similar to those generated by models that employ the traditional measures of the Focus survey published by the Brazilian Central Bank. In light of this, we can conclude that the measures of core inflation analyzed here succeeded in the objective of anchoring inflation expectations in the period analyzed.

In spite of the contributions liste above, this work suffers from limitatios of data availability. The main reason for that was the discontinuation of the montly unemployment series by the Brazilian Federal Bureau of Statistics in the year of 2015. One could resort to regional measures of unemployment to complete the series, however the degree of regional economic disparities in the country probably would bias the results. Suggestions for further research would be to update the unemployment series for more recent years and to use a non-linear HNKPC and Bayesian estimation to see if accuracy of estimates and the predictive performance of the model would be enhanced.

\section{References}

Andrade, I., \& O'Brien, R. (2001). A Measure of Core Inflation in the UK. Discussion Paper Series. In Economics and Econometrics, n. 0708. Southampton: School of Social Sciences, University of Southampton.

Areosa, W. D., \& Medeiros, M. (2007). Inflation Dynamics in Brazil: The Case of a Small Open Economy. Brazilian Review of Econometrics, 27(1), 131-166. https://doi.org/10.12660/bre.v27n12007.1575

Arruda, E. F., Ferreira, R. T., \& Castelar, I. (2011). Modelos Lineares e não Lineares da Curva de Phillips para a Previsão da Taxa de inflação no Brasil. Revista Brasileira de Economia, 65(3), 237-252. https://doi.org/10.1590/S0034-71402011000300001

Arruda, E. F., Oliveira, M. T. A., \& Castelar, I. (2017). Dinâmica Recente da Inflação Brasileira em Ambientes Distintos de Expectativas Forward-Looking. Revista de Economia Política, 37(4), 808-831. https://doi.org/10.1590/0101-31572017v37n04a09

Banco Central do Brasil. (2009). Relatório de Inflação, 11(4). Retrieved from http://www.bcb.gov.br/htms/relinf/port/2009/12/ri200912P.pdf

Baum, C. F., Schaeffer, M. E., \& Stillman, S. (2003). Instrumental Variables and GMM: Estimation and Testing. Stata Journal, 3(1), 1-31. https://doi.org/10.1177/1536867X0300300101

Baum, C. F., Schaeffer, M. E., \& Stillman, S. (2007). Enhanced Routines for Instrumental Variables/GMM Estimation and Testing. Stata Journal, 7(4), 465-506. https://doi.org/10.1177/1536867X0700700402

Blanchard, O., \& Galí, J. (2007). Real Wage Rigidities and the New Keynesian Model. Journal of Money, Credit and Banking, 39(1), 35-66. https://doi.org/10.1111/j.1538-4616.2007.00015.x 
Bryan, M. F., \& Cecchetti, S. G. (1994). Measuring core inflation. In N. G. Mankiw (Ed.), Studies in Business Cycles (p. 29). Chicago and London, University of Chicago.

Calvo, G. A. (1983). Staggered prices in a utility-maximizing framework. Journal of Monetary Economics, 12(3), 383-98. https://doi.org/10.1016/0304-3932(83)90060-0

Caner, M., \& Hansen, B. E. (2004). Instrumental variable estimation of a threshold model. Econometric Theory, 20, 813-843. https://doi.org/10.1017/S0266466604205011

Carvalho, A. R. (2014). A persistência da indexação no Brasil pós-Real. Revista de Economia Política, 34(2), 266-283. http://dx.doi.org/10.1590/S0101-31572014000200006

Correa, A. S., \& Minella, A. (2010). Nonlinear Mechanisms of the Exchange Rate Pass-Through: A Phillips Curve Model with Threshold for Brazil. Revista Brasileira de Economia, 64(3), 231-243. http://dx.doi.org/10.1590/S0034-71402010000300001

Cumby, R. E., \& Huizinga, J. (1992). Testing the Autocorrelation Structure of Disturbances in Ordinary Least Squares and Instrumental Variables Regressions. Econometrica, 60(1), 185-195. https://doi.org/10.2307/2951684

Denardin, A. A., Kozakevicius, A., \& Schmidt, A. A. (2016). Avaliação da Medida de Núcleo de Inflação Baseada no Método Wavelet para o Brasil. XIX Encontro de Economia da Região Sul - ANPEC SUL. Foz do Iguaçu, Brasil.

Diebold, F. X, \& Mariano, R. (1995). Comparing predictive accuracy. Journal of Business and Economic Statistics, 13, 253-265. https://doi.org/10.1080/07350015.1995.10524599

Eckstein, O. (1981) Core Inflation. Englewood-Cliffs, NJ: Prentice-Hall.

Ferreira, R. T., Goes, C. R. C., \& Arruda, E. (2018). Central Bank Credibility and Inflation Dynamics in Brazil. The Empirical Economics Letters, 17, 235-242.

Galí, J., \& Gertler, M. (1999). Inflation Dynamics: A Structural Econometric Analysis. Journal of Monetary Economics, 44(2), 195-222. https://doi.org/10.1016/S0304-3932(99)00023-9

Galí, J., Gertler, M., \& Lopez Salido, J. D. (2001). European Inflation Dynamics. European Economic Review, 45(7), 1237-1270. https://doi.org/10.1016/S0014-2921(00)00105-7

Giannone, D., \& Matheson, T. (2007). A new core inflation indicator for New Zealand. International Journal of Central Banking, 3(4), 145-180.

Hansen, L. P. (1982). Large Sample Properties of Generalized Method of Moments Estimator. Econometrica, 50(4), 1029-1054. https://doi.org/10.2307/1912775

Mazali, A. A., \& Divino, J. A. (2010). Real wage rigidity and the New Phillips curve: The Brazilian case. Revista Brasileira de Economia, 64(3), 291-306. https://doi.org/10.1590/S0034-71402010000300005

Mendonça, M. J. C., Sachsida, A., \& Medrano, L. (2012). Inflação versus Desemprego: Novas Evidências para o Brasil. Economia Aplicada, 16, 475-500. https://doi.org/10.1590/S1413-80502012000300006

Pagan, A. R., \& Hall, D. (1983). Diagnostic Tests as Residual Analysis. Econometric Review, 2(2), 159-218. https://doi.org/10.1080/07311768308800039

Phillips, A. W. (1958). The relation between unemployment and the rate of change of money wage rates in the $\begin{array}{llll}\text { United } & \text { Kingdom, } & \text { 1861-1957. } & \text { Economica, 253-299. }\end{array}$ https://doi.org/10.1111/j.1468-0335.1958.tb00003.x

Quah, D., \& Vahey, S. (1995). Measuring Core Inflation. Economic Journal, 105(432), September, 1130-1144. https://doi.org/10.3386/w4303

Rudd, J., \& Whelan, K. (2005). New tests of the new Keynesian Phillips Curve. Journal of Monetary Economics, 52, 1167-1181. https://doi.org/10.1016/j.jmoneco.2005.08.006

Sachsida, A. (2013). Inflação, Desemprego e Choques Cambiais: Uma Revisão da Literatura sobre a Curva de Phillips no Brasil. Revista Brasileira de Economia, 67(4), 549-559. https://doi.org/10.1590/S0034-71402013000400009

Santos, C. S. (2017). Ensaios em Econometria de Séries Temporais: núcleo e previsão da inflação no Brasil (p. 96). Tese - (Doutorado em Economia) - Universidade Federal do Ceará, Faculdade de Economia, Administração, Atuária e Contabilidade, Programa de Pós-Graduação em Economia. CAEN, Fortaleza. 
Santos, C. S., \& Castelar, I. (2016). Avaliando as Medidas de Núcleo de Inflação no Brasil. Economia Aplicada, 20(1), 35-56. https://doi.org/10.11606/1413-8050/ea134823

Taylor, J. B. (1980). Aggregate Dynamics and Staggered Contracts. Journal of Political Economy, 88, 1-23. https://doi.org/10.1086/260845

Tombini, A. A., \& Alves, S. A. L. (2006). The recent Brazilian disinflation process and costs. Central Bank of Brazil Working Paper Series, 109.

West, K. D. (2006). Forecast evaluation. In G. Elliot, C. W. J. Granger, \& A. Timmermann (Eds.), Handbook of Economic Forecasting (pp. 99-134). https://doi.org/10.1016/S1574-0706(05)01003-7

\section{Notes}

Note 1. The sample used ends in August 2015 due to the unavailability of more recent data for the unemployment series in Brazil.

Note 2. Although the sample is consistent in the presence of heteroscedasticity, the GMM estimator has weak performance in small samples. Hence, when the problem of heteroscedasticity is not present, it is preferable to employ the instrumental variables estimator (Baum, Schaffer, \& Stillman, 2003; 2007).

Note 3. A test recommended for estimation in the presence of endogenous regressors under the null hypothesis of homoscedasticity.

Note 4. When the errors are homoscedastic, Baum, Schaffer, and Stillman $(2003 ; 2007)$ showed that the use of instrumental variables is preferable, due to the weak performance of the GMM in small samples.

Note 5. The Plano Real, instituted in 1994, finally managed to tame the persistently high inflation (at times hyperinflation) that characterized the previous decade.

\section{Copyrights}

Copyright for this article is retained by the author(s), with first publication rights granted to the journal.

This is an open-access article distributed under the terms and conditions of the Creative Commons Attribution license (http://creativecommons.org/licenses/by/4.0/). 